\title{
HispanismeS
}

Revue de la Société des Hispanistes Français

$17 \mid 2021$

Murs, barrières, obstacles dans les mondes

hispaniques I

\section{El huevo y la castaña : el malentendido como agente de interculturalidad en la conquista y colonización de América}

L'œu et la châtaigne: le malentendu comme agent d'interculturalité dans la conquête et la colonisation de l'Amérique

The egg and the chesnut: Misunderstanding as an agent of interculturality in the conquest and colonization of America.

\section{Marcos Eymar}

\section{(2) OpenEdition}

\section{Journals}

Edición electrónica

URL: https://journals.openedition.org/hispanismes/15017

DOI: 10.4000/hispanismes. 15017

ISSN: 2270-0765

\section{Editor}

Société des Hispanistes Français

\section{Referencia electrónica}

Marcos Eymar, «El huevo y la castaña : el malentendido como agente de interculturalidad en la conquista y colonización de América», Hispanismes [En línea], 17 | 2021, Publicado el 01 junio 2021, consultado el 27 enero 2022. URL: http://journals.openedition.org/hispanismes/15017 ; DOI: https:// doi.org/10.4000/hispanismes.15017

Este documento fue generado automáticamente el 27 enero 2022.

\section{cc) $(\mathrm{S})$}

Les contenus de cette revue sont mis à disposition selon les termes de la Licence Creative Commons Attribution - Pas d'Utilisation Commerciale - Pas de Modification 4.0 International. 


\title{
El huevo y la castaña : el malentendido como agente de interculturalidad en la conquista y colonización de América
}

\author{
L'œuf et la châtaigne : le malentendu comme agent d'interculturalité dans la \\ conquête et la colonisation de l'Amérique \\ The egg and the chesnut: Misunderstanding as an agent of interculturality in \\ the conquest and colonization of America.
}

\section{Marcos Eymar}

1 El español, como la mayoría de las lenguas europeas, dispone de un término que designa una comprensión fallida («malentendido»), pero no del equivalente «bienentendido» para referirse a una comunicación exitosa. Ello parece sugerir que lo habitual es entenderse correctamente y que el malentendido constituye una anomalía que perturba el curso normal de la interacción lingüística. Tal concepción optimista seguramente esté justificada en el caso de los intercambios verbales cotidianos con una finalidad práctica, pero resulta mucho más incierta cuando de lo que se trata es de expresar pensamientos, sentimientos $u$ opiniones de una cierta complejidad. Ya el filósofo Fritz Mauthner escribió que, por medio del lenguaje, los hombres «habían hecho imposible conocerse unos a otros» ${ }^{1}$.

2 Si no siempre resulta fácil evitar los errores y las incomprensiones entre personas que comparten una misma lengua y cultura, ¿cómo no van a surgir constantemente entre individuos de lenguas y culturas diferentes? En tanto que manifestación histórica paradigmática del encuentro con el otro, la conquista y la colonización europea de América ofrece un abundante muestrario de las diversas formas del malentendido que el presente trabajo se propone explorar. En una primera parte recordaré el desafío que supuso para los españoles la extraordinaria variedad lingüística del continente americano para, a continuación, exponer cómo ésta contrariaba la voluntad 
imperialista de los europeos, la cual presuponía la exigencia de la comunicación. Desde esta perspectiva, las dificultades de comprender y hacerse comprender aparecían como un irritante obstáculo que, en numerosas ocasiones, fue negado para dar lugar a numerosos malentendidos etnocéntricos, fundados en el desconocimiento de la alteridad. No obstante, esta visión y función puramente negativas del malentendido no son las únicas posibles. En la última parte de este trabajo, inspirándome en las ideas de Franco La Cecla, intentaré demostrar cómo las barreras de los malentendidos contribuyeron a evitar la destrucción total de las civilizaciones aborígenes y a crear la cultura sincrética característica de Hispanoamérica.

\section{Las barreras babélicas}

3 Cuando se evocan los tremendos obstáculos a los que hubieron de enfrentarse los españoles en la conquista y colonización de América, se suele citar elementos naturales como las selvas y las cordilleras impenetrables, los huracanes y las tormentas, las enfermedades tropicales o, ya en el plano humano, la resistencia militar que no pocos pueblos indígenas opusieron al avance de los invasores. No obstante, junto con todas estas dificultades, hubo otras barreras de índole cultural que no podían salvarse con la resistencia física ni la fiereza bélica que han forjado la equívoca leyenda de los conquistadores: me refiero a los problemas de comunicación derivados de la extrema diversidad lingüística y cultural del continente americano.

4 En la Edad Media solía establecerse en 72 el número de lenguas producidas por el castigo de Babel. A esta cifra se llegaba sumando los descendientes de Noé citados en el capítulo 10 del Génesis: 15 de Jafet, 30 de Cam y 27 de Sem. Sin embargo, encontramos pocas listas completas de estas lenguas: sin duda a los letrados medievales les costaba encontrar tantos idiomas que citar. La expansión portuguesa por la costa occidental de África a lo largo del siglo XV había puesto en contacto a los europeos con numerosas lenguas desconocidas hasta entonces. Pero los portugueses no establecieron relaciones duraderas con esas poblaciones más allá de los intercambios comerciales y sabemos que en muchos casos se practicaba el llamado "comercio silencioso», que prescindía casi por completo de la palabra ${ }^{2}$. En estas circunstancias, el descubrimiento de América supuso un auténtico «shock» lingüístico, como queda claro en una de las primeras cartas de Américo Vespuccio: «Y apresamos obra de 20 de aquellos [indios], entre los cuales había 7 lenguas, que no se entendían la una con la otra: se dice que en el mundo no hay más que 77 lenguas, y yo digo que son más de 1000, porque sólo aquellas que yo he oído son más de $40 »^{3}$.

5 Los lectores de Américo debieron de pensar que el explorador italiano exageraba. Hoy sabemos que no era así. Se calcula que antes de la llegada de los europeos existían en el continente un mínimo de 1.500 lenguas, pertenecientes a alrededor de 170 familias lingüísticas ${ }^{4}$. El jesuita José de Acosta describe América como «una espesa selva de idiomas» ${ }^{5}$. En el mismo sentido el cronista Cieza de León, a propósito de la provincia de Arma en el Perú, afirma que «casi en cada barrio y loma hay lengua diferente» ${ }^{6}$. En 1580 Miguel Cabello de Balboa apuntaba el caso de familias donde hombres y mujeres de un mismo grupo hablaban entre sí lenguas diferentes. Probablemente se trataba de ceremonias rituales, pero para el clérigo español era una prueba de la confusión babélica que reinaba en América. En la crónica de la expedición de Hernando de Alarcón por el sur de Estados Unidos en 1540, se utiliza el término de «lengua» como 
sinónimo de "pueblo» al evocarse el caso de un río «que estaba habitado por 23 lenguas diferentes» ${ }^{7}$. "Cada provincia, cada nación, y en muchas partes cada pueblo, tenía su lengua por sí, diferente de sus vecinos» escribió el Inca Garcilaso ${ }^{8}$.

6 Los inconvenientes de semejante situación eran obvios para los invasores, pues la fragmentación lingüística dificultaba la obtención de información y, por ende, la búsqueda de los dos objetivos inmediatos de los españoles: comida y oro. Abundan en las crónicas de Indias las quejas ante los problemas que planteaba la imposibilidad de entender a los indios y hacerse entender por ellos. «Uno de los mayores trabajos, que por estos países afligieron a Benalcázar, fue la diferencia de idiomas, que encontraba en cada uno» escribió Lucas Fernández de Piedrahita a propósito de la expedición de Benalcázar en la actual Venezuela entre 1535 y $1540^{9}$. Álvar Núnez Cabeza de Vaca compara la ausencia de lengua, es decir, de «intérprete», con una forma de mudez: «ívamos mudos y sin lengua, por donde mal nos podíamos entender con los indios, ni saber lo que de la tierra queríamos» ${ }^{10}$.

$7 \quad$ En los primeros contactos entre indios y españoles el lenguaje no verbal desempeñaba un papel insustituible. Expresiones como «señalar», «preguntar por señas», «responder por señas» o "hablar por señas» son recurrentes en las crónicas ${ }^{11}$. No obstante, las técnicas para superar las barreras idiomáticas eran variadas $\mathrm{y}$, en ocasiones, pintorescas. Fray Gaspar de Carvajal nos informa de que Francisco de Orellana, el primer explorador europeo del río Amazonas, se comunicaba con los indios «gracias a un vocabulario que había fecho» ${ }^{12}$. Francisco de Gomara nos cuenta cómo el conquistador de Yucatán, Francisco de Montejo, no perdía ocasión, ni siquiera cuando orinaba, de aumentar sus conocimientos lingüísticos:

Entró en Acuzamil, isla de su gobernación; y como no tenía lengua, ni entendía ni era entendido; y así estaba con pena. Meando un día tras una pared, se llegó un isleño y le dijo chuca va, que quiere decir ¿cómo se llama? Escribió luego aquellas palabras por que no se le olvidasen, y preguntando con ellas por cada cosa, vino a entender los indios, aunque con trabajo, y túvolo por misterio ${ }^{13}$.

8 Algunas expediciones, como en la que participó el alemán Federmann, llegaron a reunir cinco intérpretes de cinco lenguas distintas con la esperanza de poder entenderse con la asombrosa variedad de pueblos que atravesaban: «No hay duda de que antes de que nuestros discursos llegasen a la quinta persona, cada quien había cambiado o agregado algo, de modo que de cada diez de mis palabras apenas una llegaría a mi interlocutor ${ }^{14}$.

Los desafíos eran todavía mayores para los misioneros, ya que estos no solo trataban de obtener información práctica, sino de iniciar a los indígenas en los misterios de la fe católica. ¿Cómo explicar conceptos tan complejos como «eucaristía», «transubstanciación», «trinidad», «crucifixión», «alma» o «pecado»? La dificultad estribaba no solo en dominar idiomas tan difíciles como el de los indios machicuis que, en palabras de Félix de Azara, «uno se admira de que lo aprendan los hijos de sus padres $»^{15}$, sino en que algunas de estas lenguas carecían de los conceptos abstractos más elementales para un hablante occidental como «vida», «muerte», «inteligencia», «voluntad», «memoria», «honra», «paz» ${ }^{16} \ldots$ En estas condiciones, no resulta sorprendente que algunos misioneros, como el jesuita Joseph Gumilla, sintieran «frío y congoja» ante «la excesiva velocidad de las lenguas guajira, chiricoa, otomaca y garaúna» ${ }^{17}$.

10 Todos los testimonios citados, a los que se podrían añadir abundantes ejemplos análogos, consideran tácitamente la variedad lingüística según el paradigma babélico, 
como una calamidad, expresión de la confusión y del castigo divino. No obstante, considerar que la dificultad de comunicarse fue un "obstáculo» o una «barrera», implica adoptar una perspectiva occidental. Sabemos que, para muchos pueblos indígenas, su idioma (para el que, a menudo, no existía un nombre específico y que numerosos pueblos designaban simplemente como «la lengua», «nuestra lengua» o «el habla verdadera» ${ }^{18}$ constituía el fundamento de su identidad. Los colonos europeos se sorprendían de que pueblos vecinos que, en apariencia, no se distinguían por sus costumbres, tuviesen lenguas muy diferentes ${ }^{19}$. A diferencia de lo que ocurría en México central y en Perú, donde el náhuatl y el quechua funcionaban como linguas francas, en vastas zonas del continente no existía esa tendencia unificadora: frente a la función comunicativa primaba la función cohesionadora. La colonización no hizo sino reforzar esta oposición. Para los europeos, la extrema fragmentación idiomática del continente americano aparecía como una traba a su anhelada expansión; en cambio, desde una perspectiva indígena, la diferencia lingüística actuó como un parapeto defensivo que retrasó y, en muchos casos, evitó, una victoria y asimilación culturales totales.

\section{El imperio de la comunicación}

11 En su libro La découverte de l'Amérique. La question de l'autre (1982), Tzvetan Todorov plantea la hipótesis de que una de las claves del rápido triunfo español en episodios como la conquista de México radicó en su interés por el lenguaje y los signos como medio de comunicación y manipulación entre los hombres y no, como en el caso de la cultura mexica, como modo de relacionarse con el mundo y los dioses ${ }^{20}$. A lo largo de su itinerario desde la costa del Golfo de México hasta Tenochtitlán, Hernán Cortés hizo gala de una enorme habilidad para controlar la información, dosificándola o distorsionándola en función del efecto que había de producir en sus interlocutores y de sus propios intereses. Para Todorov, esta capacidad para adaptar estratégicamente el propio mensaje a individuos de una cultura desconocida es una prueba del carácter «alocéntrico» de la civilización occidental europea: el Occidente cristiano tenía sus bases históricas y espirituales en lugares periféricos con respecto a ella misma, como Atenas y Jerusalén, y, además, a lo largo de su desarrollo, se había enfrentado a otras civilizaciones rivales muy distintas, como el Islam $^{21}$. A diferencia de los pueblos prehispánicos, que nunca habían tenido contacto con pueblos radicalmente otros, los europeos, y muy especialmente los castellanos después de muchos siglos de lucha contra los musulmanes, estaban acostumbrados a enfrentarse a la alteridad.

Para los europeos del siglo XVI existía un vínculo muy claro entre la comunicación y el poder. Mediante su célebre fórmula inserta en el prólogo a su Gramática castellana de 1492 («Siempre fue la lengua compañera del imperio»), Antonio de Nebrija, inspirándose en autores anteriores como Lorenzo Valle o Mícer Gonzalo, afirmaba que «la lengua acompaña al proceso orgánico de la suprema creación del hombre: el Estado, con el que florece y se marchita» ${ }^{22}$. La gramática contribuía a reforzar el poder de un estado no solo porque «fijase» la lengua y retrasase su inevitable declive, sino también porque facilitaba que otros pueblos la aprendiesen:

después que vuestra Alteza metiesse debaxo de su iugo muchos pueblos bárbaros y naciones de peregrinas lenguas, y con el vencimiento aquellos ternían necessidad de recebir las leies quel vencedor pone al vencido, y con ellas nuestra lengua, 
entonces, por esta mi arte, podrían venir en el conocimiento della, como agora nos otros deprendemos el arte de la gramática latina para deprender el latin ${ }^{23}$. del colonizador es que no va a ser entendido por el colonizado porque éste no comparte una forma de vivir en la que la razón caracteriza la comunicación $»^{24}$, considero que lo propio del imperialismo occidental es su propósito de comprender y ser comprendido, aunque solo sea con el fin instrumental de imponer universalmente su visión del mundo. Una vez más el ejemplo de la conquista de México nos ofrece un ejemplo llamativo de esta actitud: mientras que Hernán Cortés, a lo largo de su avance por México, insiste una y otra vez en comunicarse con Moctezuma; éste, según las crónicas indígenas, trata de escapar a la necesidad de entrevistarse con los recién llegados: «cuando oía Motecuhzoma que mucho se indagaba sobre él, que se escudriñaba su persona, que los "dioses" mucho deseaban verle la cara, como que se le apretaba el corazón, se llenaba de grande angustia (...) Se les quería esconder, se les quería escabullir a los "dioses" ${ }^{25}$.

El término «deshumanización» con el que a menudo se califica el trato que los colonos reservaban a los indígenas ha de interpretarse en un sentido puramente metafórico. $\mathrm{Si}$, como se colige de la cita anterior, pudo existir en un primer momento cierta indecisión por parte de los indígenas acerca de la naturaleza humana de los españoles, estos últimos nunca albergaron dudas acerca de la humanidad de los indios. Ello no quiere decir, por supuesto, que consideraran a los conquistados como iguales; antes bien, la común humanidad constituyó el fundamento sobre el cual se erigió la implacable jerarquía de la colonización. Nunca ha sido necesario negar la humanidad del prójimo para explotarlo sin escrúpulos. Tal y como escribe Jacques Rancière: «Pas de service qui s'exécute, pas de savoir qui se transmette, pas d'autorité qui s'établisse sans que le maître ait, si peu que ce soit, à parler "d'égal à égal" avec celui qu'il commande ou instruit. La société inégalitaire ne peut fonctionner que grâce à une multitude de relations égalitaires» ${ }^{26}$. Se ha señalado que el primer delito que los españoles cometen en el Nuevo Mundo tuvo una finalidad lingüística: se trata del rapto de siete indígenas taínos para llevárselos a España «y que aprendan a hablar» ${ }^{27}$. Disponer de intérpretes lo más rápidamente posible era importante no únicamente por las razones prácticas de obtener información y oro, sino también porque permitía afirmar el propio poder mediante el acto imperialista por antonomasia de ordenar y ser obedecido: «Ellos deben ser buenos servidores y de buen ingenio, que veo que muy presto dicen todo lo que les decía» (Colón, Diario de abordo, 11 de octubre de 1492); «y así son buenos para les mandar y les hacer trabajar y sembrar, y hacer todo lo otro que fuese menester, y que hagan villas y se enseñen a andar vestidos y a nuestras costumbres.» (Colón, Diario de abordo, 16 de diciembre de 1492).

Sin duda, esta necesidad de mandar explica que todos los imperios hayan promovido el uso de una lengua común entre los pueblos conquistados. También, como he apuntado anteriormente, los mexicas y los incas fomentaron el uso del náhuatl y del quechua en los territorios que dominaban. No obstante, la diferencia de la conquista española de América con otros proyectos colonizadores anteriores estriba en su dimensión proselitista, mesiánica y universalista. El objetivo último de los españoles era crear una Monarquía Católica Universal: un solo pueblo, un solo rey, una sola religión. Los españoles no se conformaban con explotar las riquezas y el trabajo de los indígenas; codiciaban también sus almas o, en términos contemporáneos, su «imaginario». Sustituir activamente la religión de los pueblos conquistados, y no como resultado de un

HispanismeS, 17 | 2021 
proceso secular de emulación, como sucedió en el imperio romano, implicaba buscar acceso a los estratos psíquicos más profundos del individuo y, por consiguiente, ahondar y multiplicar las necesidades comunicativas.

La importancia que Colón, Cortés y otros exploradores y conquistadores atribuyen a la lengua en la colonización alcanza en «la conquista espiritual» de los indígenas una nueva dimensión. En 1536 la Corona española dio instrucción al virrey Mendoza de México para que los frailes aprendiesen la lengua de los indios e hicieran arte, es decir gramática, de ella. En su tratado de evangelización titulado De procuranda indorum salute (1588), José de Acosta sostuvo que, para un misionero en América, aprender el idioma de los indios debía ser «su primera e incansable preocupación» ${ }^{28}$. Mercuriano, general de los jesuitas, afirmaba que los jesuitas hablaban las lenguas indígenas entre sí y su sucesor, Aquaviva, se hizo eco inmediata y espontáneamente de un decreto de Felipe II y mandó que nadie se ordenara sacerdote sin saber la lengua. Algunos religiosos se convirtieron en auténticos políglotas. Quizás el ejemplo más llamativo entre los jesuitas fuera el del padre Berzana. Empezó a estudiar quechua en el barco. A los cuatro meses de estar en Perú ya predicaba. Al fin de su vida hablaba nueve lenguas indígenas. Su compañero Añasco escribe a Aquaviva desde Tucumán: «Podemos por la voluntad del Señor catequizar y confesar en once lenguas... y todas las salidas que hacemos traemos aprendidas una o dos lenguas $»^{29}$. Los misioneros no solo aprendieron lenguas indígenas, sino que también escribieron centenares de gramáticas que constituyen las primeras gramáticas de lenguas no occidentales escritas por europeos. Los misioneros compusieron catecismos, vocabularios y artes gramaticales de lenguas como el otomí, totanco, zapoteco, tarasco, maçahua, cakchiquel y maya para Mesoamérica; del mapuche, aimara, moxa, yunga, culle, cumanagota, lule, milcayac y un largo etcétera para la América meridional. En el caso de las llamadas «lenguas generales» cabe hablar de auténticas «escuelas lingüísticas» ${ }^{30}$ : relacionadas con el náhuatl se compusieron sesenta y seis gramáticas y veintiuna del quechua.

17 Todo este impresionante esfuerzo lingüístico, del que no he ofrecido más que un brevísimo esbozo, tenía por objetivo último la erradicación de las religiones indígenas. Los misioneros buscaban comprender la lengua indígena para sustituir su cultura por otra. El modelo de la mayor parte de las gramáticas misioneras fue la gramática de Nebrija: se trataba, como ya había hecho el humanista español con el castellano, de «reducir» las peculiaridades de las lenguas americanas a los moldes de la gramática latina. Que el verbo «reducir» se utilizase también en la época como sinónimo de «sedentarizar» - las Leyes de Burgos (1512) expresaban la necesidad de que «los dichos yndios avian de seer doctrinados e enseñados e traydos al conoscimiento de nuestra ssanta fee catolica e ansimismo tratados e reduzidos a pueblos» ${ }^{31}$-muestra a las claras que la codificación de los idiomas indígenas no era sino la manifestación lingüística del proceso colonizador. En este contexto, la comunicación implicaba, necesariamente, la asimilación total y la alteridad solo podía ser concebida como un obstáculo a un impulso que no reconocía límite alguno, ni interior ni exterior. De esta conjunción de la presencia, a una escala sin parangón, de la alteridad cultural, y del empeño, no menos inédito, por comprenderla para poder aniquilarla surgió la que es una de las grandes constantes de la historia americana: el malentendido. 


\section{El malentendido etnocéntrico}

18 El descubrimiento de América se basó en el que es quizás el más célebre malentendido de la historia: Colón pretendía llegar a Asia y se topó con un continente ignorado por los europeos, aunque se resistiese a reconocerlo hasta su muerte. Ese equívoco inicial se prolongó en la consideración de América como un «Nuevo Mundo», puesto que, como observa Walter Mignolo, la presunta «novedad» del continente constituía un contrasentido que «suprimía las descripciones de los habitantes del lugar y para los cuales nada era nuevo, excepto la llegada de un grupo de personas provenientes de un mundo nuevo y desconocido» ${ }^{32}$. Empezando por el propio término de «las Indias» $\mathrm{y}$ «los indios», dominante a lo largo del período colonial, la toponimia americana ofrece abundantes testimonios de ese malentendido fundacional presente en el mismo acto de nombrar las tierras que se conquistaban. Las Casas recuerda que los españoles, en un primer momento, a la isla de Haití la llamaron «Bohío», que era el equivalente taíno de «casa»"33. En el preámbulo a las Cartas de relación de Hernán Cortés, no escrito por el propio conquistador, se explica así el origen del nombre «Yucatán»:

$\mathrm{Y}$ es de saber que los primeros descubridores de la dicha tierra fueron otros y no el dicho Diego Velázquez, según adelante parecerá, los cuales, no sabiendo lo que se decían, la intitularon y llamaron Yucatán, porque los dichos primeros descubridores, como llegasen acá y preguntasen a los indios naturales de la dicha tierra que cómo se llamaba aquella tierra, y los indios no entendiendo lo que les preguntaban, respondían en su lenguaje y decían Yucatán, Yucatán, que quiere decir no entiendo, no entiendo: así los españoles descubridores pensaron que los indios respondían que se llama Yucatán ${ }^{34}$.

19 Según el Inca Garcilaso, un malentendido semejante se halla en el origen del topónimo «Perú»:

Los españoles, habiéndole acariciado porque perdiese el miedo que de verlos con barbas y en diferente traje que el suyo había cobrado, le preguntaron por señas y por palabras qué tierra era aquella y cómo se llamaba. El indio, por los ademanes y meneos que con manos y rostros le hacían (como un mudo) entendía que le preguntaban, mas no entendía lo que le preguntaban, y a lo que entendió que era el preguntarle, respondió aprisa (antes que le hiciese algún mal) y nombró su propio nombre diciendo Benú, y añadió otro y dijo Pelú. Quiso decir, si me preguntais como me llamo, yo me digo Berú; y si me preguntáis donde estava, digo que estaba en el Río, porque es de saber que el nombre Pelú, en el lenguaje de aquella Provincia, es nombre apelativo y significa Rio en común (...) Los Christianos entendieron, conforme a su deseo, imaginando que el indio les avia entendido, y respondiendo a propósito, como si él, y ellos huveran hablado en Castellano, y desde aquel tiempo, que fue el año de mil quinientos y quince, o diez y seis, llamaron Perú aquel riquissimo y grande Imperio, corrompiendo ambos nombres, como corrompen los Españoles casi todos los vocablos que toman del lenguaje de los Indios de aquella Tierra $^{35}$.

20 Esta cita permite reconstruir las etapas conducentes al malentendido: la presencia de una alteridad incomprensible («barbas y diferente traje»); el miedo; los intentos de comunicación no verbal; la conciencia de una voluntad de saber por parte del otro, aunque no se comprenda el contenido de lo que se quiere saber; y, factor esencial, una predisposición de los españoles a entender al otro «conforme a su deseo». En su análisis del malentendido Vladimir Jankélevitch atribuye a la «mitomanía del deseo» una parte importante de la tendencia humana «de ne pas écouter et de lire ses propres intentions dans la parole d'autrui, opposant au doute, à l'objectivité, à la raison impartiale, à la 
sagesse le mur infranchissable de sa créance» ${ }^{36}$. No hay colonización sin deseo - deseo de riqueza, de gloria, de aventura, de evangelización. En el caso del primer viaje colombino, uno de los mayores anhelos del explorador genovés, tal y como explica en el prólogo a su Diario de a bordo, era entrar en contacto con el «Gran Can», el poderoso emperador de China del que hablaba Marco Polo ${ }^{37}$. Y eso es exactamente lo que Colón creyó comprender el treinta de octubre por boca de los taínos de las Antillas, a más de trece mil kilómetros de las costas asiáticas: «el rey de aquella tierra tenía guerra con el Gran Can, al cual ellos llaman Camy, y a su tierra o ciudad Saba, y otros muchos nombres $»^{38}$. Comentando este y otros pasajes en que los españoles comprenden lo que quieren comprender, Bartolomé de las Casas observa con lucidez: «es cosa maravillosa cómo lo que el hombre mucho desea y asienta una vez con firmeza en su imaginación, todo lo que oye y ve, ser en su favor a cada paso se le antoja $»^{39}$.

El filósofo Eugenio Trías escribe que «en el orden del deseo siempre subsiste un sujeto deseante perpetuamente insatisfecho en lo más íntimo y un objeto destinado a ser negado y devorado, que deja paso, una vez destruido, a otro objeto» ${ }^{40}$. Esta reflexión sobre el eros bien puede aplicarse también al proceso colonizador, donde los europeos deseantes negaron, devoraron simbólicamente y destruyeron buena parte de las culturas indígenas. La proyección en el continente recién descubierto de sueños, mitos y utopías (ya fueran la China de Marco Polo, Eldorado o el Edén) exigía aplicar el principio de tabula rasa ${ }^{41}$, eliminando todos aquellos elementos autóctonos que pudieran contradecir la lógica narcisista del deseo colonizador.

En cierto sentido este fenómeno obedece al hecho de que «la mente humana tiene una innata necesidad de apoyarse en los objetos que le son familiares y en las imágenes-tipo para adaptarse al choque con lo desconocido» ${ }^{42}$. Para los europeos estas imágenes-tipo tenían dos principales procedencias: la tradición clásica greco-latina y la tradición cristiana. Dos breves ejemplos: cuando Fray Gaspar de Carvajal, capellán de la expedición de Francisco de Orellana, observa que diez o doce mujeres participan en la refriega de los españoles con los indios, concluye que estos últimos «son sujetos y tributarios de las Amazonas ${ }^{43}$, creencia que daría su nombre actual al río más caudaloso del planeta; en la zona de Yucatán, los españoles encontraron «unas señales como a manera de cruces $»^{44} \mathrm{y}$ no tardaron en atribuirlas a la posible existencia de una evangelización anterior, cuando, en realidad, era un símbolo asociado al agua y también al árbol yaxche, auténtico axis mundi de los mayas, que se alzaba en el centro del mundo y llegaba hasta el cielo ${ }^{45}$.

El malentendido surge pues de la zona equívoca entre la diferencia y la semejanza ${ }^{46}$, pero también de una confianza desmedida en la capacidad de comunicarse. A pesar de todas las quejas sobre la diversidad y dificultad de las lenguas indígenas que he citado en el primer apartado de este artículo, lo que llama la atención, globalmente, es la convicción de los colonos de que son capaces de superarlas. En el ejemplo del Inca Garcilaso ya analizado el deseo de los españoles los lleva a imaginar «que el indio les avia entendido, y respondiendo a propósito, como si él, y ellos huveran hablado en Castellano». Dicho de otra manera: la negación de la alteridad indígena se acompaña de una minimización de las barreras lingüísticas que los separan de los españoles. No es casual que Bartolomé de las Casas, el más eminente defensor de los indios, sea también el cronista que con mayor energía censura la inocencia o arrogancia de sus compatriotas a este respecto: 
Dice Américo [Vespucci] que después de baptizados decían los indios charaibí, que suena en su lengua (llamando a sí mismos), varones de gran sabiduría. Cosa es ésta de reír, porque aun no entendiendo qué vocablo tenían por pan o por agua, que es lo primero que de aquellas lenguas a los principios aprendemos, y en dos días o diez que allí estuvieron, Américo hace entender que entendía que charaibí quería decir varones de gran sabiduría ${ }^{47}$.

Más allá de este ejemplo concreto, el escepticismo de De las Casas se extiende a todas las observaciones de los españoles que se fundan en la interpretación de las palabras de los indígenas y no en la observación personal de hechos:

Todas estas cosas cuenta Américo en su primera navegación, muchas de las cuales no era posible en dos y en tres, ni en diez días que podían estar o estaban entre los indios, no entendiéndoles palabra una ni ninguna (...). Y por esto, sólo aquello que por los ojos vían o podían ver, como era lo que comían y bebían, y que andaban desnudos y eran de color tal y grandes nadadores y otros actos exteriores, lo podemos creer; lo demás parece todo ficciones ${ }^{48}$.

Para un lector occidental es tentador dejarse llevar por el pintoresquismo de las crónicas de Indias y olvidar la precariedad de muchas de las informaciones que contienen, aceptables únicamente mediante el «olvido u omisión de las colosales diferencias lingüísticas entre las culturas en contacto» ${ }^{49}$. ¿Por qué los cronistas europeos obvian en la mayoría de los casos este esencial condicionante de su experiencia? Un factor importante es la voluntad de no menoscabar la autoridad del propio testimonio en textos que, a menudo, se dirigían a personajes o instituciones influyentes - reyes, virreyes, arzobispos, el Consejo de Indias... - y que, con frecuencia, pretendían también dejar constancia de un «servicio» del cual se esperaba, abierta o tácitamente, una «merced $»^{50}$. No obstante, más allá de estas razones prácticas, la creencia de que se comprendía a los indios y se era comprendido por ellos casaba bien con el imperialismo de la comunicación al que antes he aludido. Dicha confianza permitía establecer una jerarquía mediante la cual los españoles se reservaban el papel activo de «inquirir», «ordenar» y «evangelizar» y los indios se veían reducidos al papel pasivo de informantes o ejecutantes. Aceptar que el castellano pudiese no ser comprendido en absoluto por los indios suponía cuestionar la universalidad que los europeos atribuían a su propia cultura cristiana ${ }^{51}$; a un nivel más profundo, la incomprensión postulaba de facto una forma de igualdad entre las dos culturas, equiparadas en la mutua ignorancia, algo que contrariaba la seguridad de los europeos en su propia superioridad. Como escribió De las Casas, criticando la consideración de los indios como bárbaros: "Y así estas gentes de estas Indias, como nosotros las estimamos por bárbaras, ellas también, por no entendernos, nos tenían por bárbaros ${ }^{52}$. La comunicación no podía ser, en este contexto, más que un espejismo, y el malentendido, del que ni siquiera se era plenamente consciente, la venganza de una realidad cuya diferencia ni siquiera era reconocida como tal. Alcanzar un conocimiento más profundo del otro implicaba, en primer lugar, asumir las barreras muchas veces infranqueables que se erigían entre los pueblos. No hay peor obstáculo para la auténtica comprensión de la diferencia que la creencia de que no hay obstáculo.

\section{El malentendido sincrético}

El tipo de malentendido basado en una mezcla etnocéntrica de ignorancia de la alteridad y confianza en la posibilidad de comprenderla, no es el único posible. A 
medida que los españoles conocieron mejor la realidad americana, fueron también más conscientes de su especificidad y de los peligros que encerraba el pretender encerrarla en las categorías europeas. «Todo es diferentísimo, el talento de la gente natural, la disposición de la república, el modo de gobernar», escribió Fray Tomás de Mercado en su libro de consejos a los comerciantes de Sevilla ${ }^{53}$. El riesgo de incomprensión concernía no únicamente los intercambios con los nativos, sino también con los españoles de la metrópoli, ignorantes de la realidad americana. Un gran conocedor de las Indias como el jesuita José de Acosta deplora que:

a muchas de estas cosas de Indias, los primeros españoles les pusieron nombre de España, tomados de otras cosas a que tienen alguna semejanza, como piñas, y pepinos y ciruelas, siendo que en la verdad frutas diversísimas, y que es mucho más sin comparación en lo que difieren de las que en Castilla se llaman por esos nombres ${ }^{54}$.

Y en otro pasaje de su Historia natural y moral de las Indias escribe que las especies de animales en el Nuevo Mundo son tan diversas «que querellas reducir a especies conocidas de Europa será llamar al huevo castaña» (final cap. 36). Esta toma de conciencia progresiva la encontramos también, aunque de manera por supuesto incompleta, en el Diario de a bordo de Colón, donde el optimismo inicial «Toda la lengua también es una y todos amigos.... ${ }^{55}$ ( 1 de noviembre) es sustituido por un reconocimiento más lúcido de la diversidad lingüística del Nuevo Mundo y de la dificultad de comprender a los indios: «muchas veces les entiendo una cosa por otra al contrario» ${ }^{56}$ (27 de noviembre). Unas semanas más tarde los indios le ofrecen «niamas», unas raíces «como rábanos grandes» que tienen «saber propio de castañas, y no hay quien no crea que no sean castañas $\aleph^{57}$ (13 de diciembre). A Colón le hubiera gustado que los territorios que recorría fuesen los que describió Marco Polo, y que la yuca fuese una castaña, pero, por difícil que fuera asumirlo, se vio obligado a aceptar a regañadientes que la realidad de esas nuevas tierras solo podía encajar con sus deseos al precio del equívoco y la confusión.

Si el peligro de llamar huevo a la castaña acechaba a quien pretendía explicar las Indias a sus compatriotas de ultramar en el mismo idioma, ¿qué dificultades no entrañaría traducir mundos tan disímiles en otra lengua? Los misioneros, precisamente por ser quienes más lejos llevaron el afán de comunicación, fueron también los que más profunda conciencia cobraron del problema. La visión optimista de Colón de que los indios «ligeramente se harían cristianos, que me pareció que ninguna secta tenían»" fue sustituida por una aguda conciencia de hasta qué punto la «idolatría» estaba imbricada con todos los aspectos de la cultura nativa:

Ni en paz ni en guerra, ni en el descanso ni en el trabajo, ni en la vida pública ni en la privada, nada son capaces de hacer sin que vaya por delante el culto supersticioso a sus ídolos. No se regocijan en sus bodas ni lloran en sus entierros, no dan o reciben banquetes, no salen siquiera de casa ni comienzan el trabajo sin celebrar algún sacrilegio pagano. ¡Tan oprimidos tiene el demonio sus sentidos con miserable esclavitud! ¡Con cuanta artimaña ocultan sus idolatrías y las disimulan, cuando ven que no se las dejan hacer en público! ¡Con cuánta desvergüenza pierden el seso en ellas, cuando creen que no se lo impedirán! ${ }^{59}$

Existen abundantes testimonios que demuestran que los recelos de Acosta no estaban del todo infundados. Algunos indígenas escondían sus antiguos ídolos en las iglesias, detrás de un biombo, un tabique o incluso dentro de los altares. Sahagún cuenta que numerosas estatuas de santos que eran sacadas en procesión estaban huecas y sospecha que los indígenas podían ocultar allí sus ídolos ${ }^{60}$. No obstante, los límites de la 
evangelización no se debían únicamente a las «artimañas» o el «disimulo» de los indios, sino también a las carencias y errores de los misioneros. En su libro Extirpación de la idolatría en el Perú el sacerdote Pablo José de Arriaga se lamentaba de que los indígenas recitaran el catecismo como «Papagallos, sin entender lo que dizen» y que la enseñanza que se les dispensaba contuviese «muchos errores, trastrocando, o mudando algunas, palabras o letras, con que hazen muy diverso sentido, como en el Credo por dezir Hucllachacuininta, que es la comunión, o junta de los santos, decir Pucllachacuininta, que es la burla, o trisca de los santos» ${ }^{61}$. Los evangelizadores se veían enfrentados a una temible disyuntiva: o bien utilizaban términos occidentales impenetrables para los nativos, que los repetían "como papagayos», o bien se esforzaban por traducirlos a las lenguas indígenas, lo cual, dada la complejidad fonética de estos idiomas, abría la puerta a todo tipo de equívocos, como el de confundir «comunión» con «burla». Los ejemplos de semejantes incomprensiones abundan a lo largo de la conquista espiritual del continente. Existen testimonios de rituales mayas durante la colonización en los cuales se sacrificaba a adultos o a niños en la cruz cristiana; en uno de ellos a la víctima se le extrajo el corazón dentro de la iglesia, se grabaron en él incisiones con la forma de la cruz y luego fue depositado en la boca de un ídolo identificado con el dios Itzamma ${ }^{62}$. Semejantes ceremonias horrorizaron a los franciscanos, pero, ¿acaso no podía interpretarse la inmolación de Cristo en el Gólgota como una forma sui generis de sacrificio humano?

Desde una óptica misionera cabría ver en estos malentendidos la expresión de un «fracaso». Sin embargo, tal y como sostiene Franco La Cecla en su brillante defensa del malentendido, "el malentendido es ciertamente una forma de fracaso, pero, en la medida en que es un "acontecimiento" que surge de improviso, manifiesta algo que nos devuelve la conciencia de la "experiencia del otro" en estado puro»" ${ }^{63}$. Mientras que la confianza etnocéntrica en la comunicación suponía la negación de la alteridad indígena, la revelación de incomprensiones tan dramáticas como la anteriormente citada la exponían en toda su crudeza. En ese sentido, el malentendido se convierte en «el espacio mismo en que las culturas, al descubrirse diferentes, se revelan y se enfrentan (...) en una zona neutra, en una tierra de nadie donde la identidad, o mejor, las identidades diferentes y enfrentadas pueden posicionarse ${ }^{64}$.

El miedo a la herejía provocada por lo que José de Acosta llama «enfermedad idolátrica hereditaria $\aleph^{65}$ provocó actitudes de recelo, cuando no de paranoia. Fray Durán en su Historia de las Indias observa que los indios «juntan con la fe cristiana algo del culto del demonio, y así tienen tan poco arraigada la fe, que con la misma facilidad que confiesan y creen en un Dios creerán en diez» ${ }^{66}$. Esta desconfianza explica que las analogías superficiales entre las religiones indígenas y la cristiana se vieran más «como obstáculos que como elementos favorables ${ }^{67} \mathrm{y}$ que muchos misioneros decidieran no traducir a las lenguas indígenas los términos claves de la teología católica. Las obras en náhuatl del gran misionero Bernardino de Sahagún, por ejemplo, aparecen llenas de préstamos del castellano y el latín ${ }^{68}$. Sin embargo, esta posición, que mantenía la distancia y, por tanto, el enfrentamiento, entre las dos culturas, no fue la única adoptada. Para designar el cielo cristiano, otros misioneros emplearon el término «Ilhuicatl» náhuatl que, en su origen, designaba el decimotercer estrato celeste donde moraba la dualidad creadora compuesta por Ometecuhtli y Omecíhuatl, divinidad a la cual también hacía referencia la expresión "In tloque in nahuaque», el «amo de lo cercano y lo lejano», con la cual los misioneros calificaban al Dios cristiano ${ }^{69}$. En las 
zonas guaraníes y tupinambas, los misioneros escogieron para referirse a Dios la voz «Tupá» o «cosa divina» que, en su origen, se refería al trueno ${ }^{70}$. En México las autoridades religiosas promovieron la creación de santuarios en el emplazamiento de antiguos santuarios paganos en Huejotzingo, Huexotla, Chalmita, y el muy célebre de la Virgen de Guadalupe en el Tepeyac, sobre las ruinas de un templo dedicado a la diosa Tonantzin ${ }^{71}$.

Semejantes adaptaciones despertaron una viva polémica. En una carta de 1651 el obispo de Asunción Fray Bernardino de Cárdenas denunciaba la política lingüística de los jesuitas de evangelizar en guaraní, que hacía que se introdujeran en los catecismos "palabras tan abominables, y tan en deshonor de Dios, y de su Madre, y el estar el nombre del demonio y de los ídolos puestos en lugar de Dios» ${ }^{72}$. Bernardino Sahagún critica a los predicadores que llaman a la Virgen «Tonantzin», pues

el vocablo significa de su primera imposición a aquella Tonantzin antigua, y es cosa que se debía remediar, porque el propio nombre de la Madre de Dios Señora nuestra no es Tonantizin, sino Dios y Nantzin. Parece esta invención satánica para paliar la idolatría bajo la equivocación de este nombre Tonantzin, y vienen ahora a visitar a esta Tonantzin de muy lejos, tanto como de antes ${ }^{73}$.

¿A quién adoraban en realidad los indios cuando acudían al santuario de Tepeyac? ¿A la Virgen cristiana, a la diosa prehispánica o las dos? Acaso veneraran a una creyendo venerar a la otra... Para La Cecla el sincretismo constituye un doble malentendido identitario, mediante el cual los «dominantes» y los «dominados» juegan con las expectativas del otro, simulando un parecido que no existe en la realidad ${ }^{74}$. Esa simulación, con el tiempo, acaba volviéndose inconsciente y erigiendo el malentendido en una nueva identidad. En el marco de la colonización, con una pronunciada asimetría entre los conquistadores y los conquistados, los vencedores y los vencidos, la comunicación presuponía necesariamente la imposición. En cambio, los malentendidos, derivados de las barreras lingüísticas y culturales, abrían una posibilidad de negociación y de transacción: los españoles sacrificaban la exactitud teológica para ser comprendidos por los indígenas, aunque fuera imperfectamente; estos últimos, se sometían exteriormente a la religión de los colonizadores, sin renunciar del todo a sus antiguas idolatrías. Muchos vieron en este proceso una componenda y una hipocresía, cuando no la obra del demonio; desde una perspectiva actual, cabe considerarlo como una confirmación de la idea paradójica de que, lejos de separar, los muros, las barreras y los obstáculos también pueden acercar las culturas hasta el punto de volverlas indistinguibles.

\section{BIBLIOGRAFÍA}

Xavier ALBó, «Jesuitas y culturas indígenas. Perú 1568-1606. Su actitud, métodos y criterios de aculturación», América indígena, vol. XXVI, nº 4 (octubre 1966), p. 395-445. 
Icíar ALONSO ARAGUÁs, Intérpretes de indias: La mediación lingüística y cultural en los viajes de exploración y conquista: Antillas, Caribe y Golfo de México (1492-1540), Tesis doctoral, Universidad de Salamanca, 2005.

Eugenio ASENSIO, «La lengua compañera del imperio. Historia de una idea de Nebrija en España y Portugal», Revista de Filología Española, vol. XLIII, nº 3/4 (1960).

Álvar Núñez CÁBEZA DE VACA, Naufragios, Madrid, Alianza Editorial, 2005.

Pedro CIEZA DE LEÓN, Crónica del Perú, en Obras completas, t. 1, Madrid, CSIC, 1984.

Cristóbal Colón, Diario de a bordo, Madrid, Edaf, 2006.

Lyle CAMPBELL, American Indian Languages. The Historical Linguistics of Native America, New York/ Oxford, Oxford University Press, 1997.

Hernán CORTÉs, Cartas y documentos, México, Porrúa, 1963.

Pablo Joseph DE ARRIAGA, Extirpación de la idolatría en el Perú, Lima, Librería San Martí, 1920.

José DE ACOSTA, De procuranda indorum salute, Madrid, CSIC, 1987.

José DE ACOSTA, Historia natural y moral de las Indias, Madrid, Alonso Martín, 1608.

Félix DE AZARA, Descripción e historia de Paraguay, Linkgua, Barcelona, 2019.

Fray Gaspar DE CARVAJAL, Descubrimiento del río de las Amazonas, Bogotá, Prensas de la Biblioteca Nacional, 1942.

Bartolomé DE LAS CASAS, Historia de las Indias, vols. 95 y 96, Madrid, BAE, 1957.

Inca Garcilaso DE LA VEGA, Comentarios reales de los Incas, t. 1, Lima, Editorial Universo, 1968.

Bernardino DE SAHAGÚN, Historia general de las cosas de Nueva España, México, Imprenta del Ciudadano Alejandro Valdés, 1830.

Bernal díAz DEL CASTILlo, Historia verdadera de la conquista de la Nueva España, México, Pedro Robredo, 1939.

Diego DURÁN, Historia de las Indias de Nueva España e Islas de Tierra firme, vol. I-II, México, Porrúa, 2005.

Carlos DISANDRO y Jorge STREET, La Compañía de Jesús contra la Iglesia y el Estado, La Plata, Ediciones Hostería volante, 1970.

John H. ELLIOT, El Viejo Mundo y el Nuevo. 1492-1650, Madrid, Alianza Editorial, 2000.

Nikolaus FEDERMANN, Viaje a las Indias del Mar Océano, Buenos Aires, Editorial Nova, 1945.

Lucas FERNÁNDEZ DE PIEDRAHITA, Historia general del Nuevo Reino de Granada, Bogotá, Biblioteca

Popular de Cultura Colombiana, 1942.

Joseph GumiLla, El Orinoco Ilustrado y Defendido, Caracas, Academia Nacional de la Historia, 1963.

Edward G. GRAY, New World Babel. Languages and nations in early America, Princeton, Princeton University Press, 1999.

Stephen GREENBLATT, «Learning to curse. Aspects of linguistic colonialism in the sixteenth century» in Learning to curse. Essays in early modern culture [1990], New York, Routledge, 2007.

Serge GRUZINSKI, La colonisation de l'imaginaire. Sociétés indigènes et occidentalisation dans le Mexique espagnol (XVI ${ }^{e}$-XVIII ${ }^{e}$ siècle), Paris, Gallimard, 1988. 
William F. HANKS, «Language and discourse in colonial Yucatán», Serge Grucinski y Nathan Wachtel (eds.), Le Nouveau Monde. Mondes nouveaux. L'expérience américaine, Paris, Éditions de l'École des Hautes Études en Sciences Sociales, 1996, p. 235-269.

Vladimir JANKÉLÉVITCH, Le Je-ne-sais-quoi et le presque-rien. T. 2. La méconnaissance. Le malentendu, Paris, Seuil, 1980.

Franco LA CECLA, Le malentendu, Paris, Balland, 2002.

Francisco LóPEZ DE GOMARA, Historia general de las Indias y Vida de Hernán Cortés, Caracas, Biblioteca Ayacucho, 1979.

Emma MARTINELL GIFRE, La comunicación entre indios y españoles: palabras y gestos, Madrid, Editorial Mapfre, 1992.

Walter MIGNOLO, «Misunderstanding and colonization: the reconfiguration of memory and space», Serge Grucinski et Nathan Wachtel (eds.), Le Nouveau Monde. Mondes nouveaux. L'expérience américaine, Paris, Éditions de l'École des Hautes Études en Sciences Sociales, 1996, p. 271-293.

Santiago MUÑOZ MACHADO, Hablamos la misma lengua. Historia política del español en América, desde la Conquista a las Independencias, Barcelona, Crítica, 2017.

Antonio de NEBRIJA, Gramática castellana, Edición de la Junta del Centenario, 1747.

Miguel LEÓN-PORTILLA, Visión de los vencidos, México, FCE, 1959.

Ángel RAMA, La ciudad letrada, Madrid, Fineo, 2009.

Jacques RANCIÈRE, La haine de la démocratie, Paris, La Fabrique, 2005.

Éric ROULET, L'évangélisation des Indiens du Mexique. Impact et réalité de la conquête spirituelle au XVI siècle, Rennes, Presses Universitaires de Rennes, 2008.

George STEINER, After Babel. Aspects of language and translation, Oxford, Oxford University Press, 1998.

Eugenio TRÍAs, Tratado de la pasión, Madrid, Taurus, 1979.

Gabriela Alejandra VERONELLI, «La colonialidad del lenguaje y el monolenguajear como práctica lingüística de racialización», Polifonia, Cuiabá-MT, v. 26, nº 44 (octubre-diciembre 2019), p. 147-159.

Robert RICARD, La conquête spirituelle du Mexique. Essai sur l'apostolat et les méthodes missionnaires des Ordres Mendiants en Nouvelle Espagne de 1523-24 à 1572, Paris, Institut d'Ethnologie, 1933.

Tzvetan todorov, La conquête de l'Amérique. La question de l'autre, Paris, Seuil, 1982.

Americo VESPUCCI, Cartas de viaje, Madrid, Alianza, 1986.

Otto zWARTJE (ed.), Las gramáticas misioneras de tradición hispánica (siglos XVI-XVII), Rodopi, 2000.

\section{NOTAS}

1. Citado por George STEINER, After Babel. Aspects of language and translation, Oxford University Press, 1998, p. 181.

2. Emma MARTINELL GIFRE, La comunicación entre indios y españoles: palabras y gestos, Madrid, Editorial Mapfre, 1992, p. 239.

3. Americo VESPUCCI, Cartas de viaje, Madrid, Alianza, 1986, p. 62. 
4. Santiago mUÑOZ MACHADO, Hablamos la misma lengua. Historia política del español en América, desde la Conquista a las Independencias, Barcelona, Crítica, 2017, p. 46. Las cifras son muy difíciles de establecer. Todavía a finales del siglo XX, las estimaciones de lenguas en el Continente variaban entre 400 y 2.500, y el número de familias lingüísticas entre 1 y 200 (Lyle CAMPBELL, American Indian Languages. The Historical Linguistics of Native America, New York/Oxford, Oxford University Press, 1997, p. 4).

5. José DE ACOSTA, De procuranda indorum salute, Madrid, CSIC, 1987, p. 65.

6. Pedro CIEZA DE LEóN, Crónica del Perú, en Obras completas, Madrid, CSIC, 1984, t. 1, p. 29.

7. Citado por Edward G. GRAY, New World Babel. Languages and nations in early America, Princeton, Princeton University Press, 1999, p. 12.

8. Inca Garcilaso DE LA VEGA, Comentarios reales de los Incas, Lima, Editorial Universo, 1968, t. 1, p. 45.

9. Lucas FERNÁNDEZ DE PIEDRAHITA, Historia general del Nuevo Reino de Granada, Bogotá, Biblioteca Popular de Cultura Colombiana, 1942, p. 202.

10. Álvar Núñez CÁBEZA DE VACA, Naufragios, Madrid, Alianza Editorial, 2005, p. 76.

11. Emma MARTINELL GIFRE, La comunicación entre indios y españoles: palabras y gestos, op. cit., p. 130-134.

12. Fray Gaspar DE CARVAJAL, Descubrimiento del río de las Amazonas, Bogotá, Prensas de la Biblioteca Nacional, 1942, p. 35.

13. Francisco LóPEZ DE GOMARA, Historia general de las Indias y Vida de Hernán Cortés, Caracas, Biblioteca Ayacucho, 1979, p. 77.

14. Nikolaus fEDERMANN, Viaje a las Indias del Mar Océano, Buenos Aires, Editorial Nova, 1945, p. 82.

15. Félix DE AZARA, Descripción e historia de Paraguay, Linkgua, Barcelona, 2019, p. 149.

16. Juan Jacobo Baegert, Noticias de la península americana de la California (1772) citado en Santiago MUÑOZ MACHADO, Hablamos la misma lengua, op. cit., p. 185.

17. Joseph Gumilla, El Orinoco Ilustrado y Defendido, Caracas, Academia Nacional de la Historia, 1963, p. 296-297.

18. Lyle CAMPBELL, American Indian Languages. The Historical Linguistics of Native America, op. cit., p. 5.

19. Edward G. GRAY, New World Babel. Languages and nations in early America, op. cit., p. 20.

20. Tzvetan todorov, La conquête de l'Amérique. La question de l'autre, Seuil, 1982, p. 107.

21. Ibid., p. 114-115.

22. Eugenio ASENSIO, «La lengua compañera del imperio. Historia de una idea de Nebrija en España y Portugal», Revista de Filología Española, vol. XLIII, no 3/4 (1960), p. 407.

23. Antonio de NEBRIJA, Gramática castellana, Edición de la Junta del Centenario, 1747, p. IV.

24. Gabriela Alejandra VERONELLI, «La colonialidad del lenguaje y el monolenguajear como práctica lingüística de racialización», Polifonia, Cuiabá-MT, v. 26, nº 44 (octubre-diciembre 2019), p. 156.

25. León PORTILLA, Visión de los vencidos, México, FCE, 1959, p. 52.

26. Jacques RANCIÈRE, La haine de la démocratie, Paris, La Fabrique, 2005, p. 55.

27. Stephen GREENBLATT, «Learning to curse. Aspects of linguistic colonialism in the sixteenth century» in Learning to curse. Essays in early modern culture [1990], New York, Routledge, 2007, p. 24.

28. José DE ACOSTA, De procuranda indorum salute, op. cit., p. 49.

29. Xavier ALBó, «Jesuitas y culturas indígenas. Perú 1568-1606. Su actitud, métodos y criterios de aculturación», América indígena, vol. XXVI, n. 4 (octubre 1966), p. 402-406.

30. Otto zWARTJE (éd.), Las Gramáticas Misioneras de Tradición Hispánica (siglos XVI-XVII), Rodopi, 2000, p. 3.

31. Texto de las Leyes de Burgos disponible en ligne <URL: https://www.uv.es/correa/troncal/ resources/leyesburgos1512.pdf>. 
32. Walter MIGNOLO, «Misunderstanding and colonization: the reconfiguration of memory and space», en Serge Grucinski y Nathan Wachtel (dirs.), Le Nouveau Monde. Mondes nouveaux. L'expérience américaine, Paris, Éditions de l'École des Hautes Études en Sciences Sociales, 1996, p. 272.

33. Bartolomé DE LAS CASAS, Historia de las Indias, Madrid, BAE, 1957, vols. 95 y 96, p. 153.

34. Hernán CORTÉs, Cartas y documentos, México, Porrúa, 1963, p. 4.

35. Inca Garcilaso DE LA VEGA, Comentarios reales de los Incas, t. 1, Lima, Editorial Universo, 1968, p. 24.

36. Vladimir JANKÉLÉVITCH, Le Je-ne-sais-quoi et le presque-rien. T. 2. La méconnaissance. Le malentendu, Paris, Seuil, 1980, p. 189.

37. Cristóbal colón, Diario de a bordo, Madrid, Edaf, 2006, p. 66.

38. Ibid., p. 119.

39. Bartolomé DE LAS CASAS, Historia de las Indias, op.cit., p. 157.

40. Eugenio TRÍAs, Tratado de la pasión, Madrid, Taurus, 1979, p. 125.

41. Ángel RAMA, La ciudad letrada, Madrid, Fineo, 2009, p. 33.

42. John H. ELLIOT, El Viejo Mundo y el Nuevo. 1492-1650, Madrid, Alianza Editorial, 2000, p. 39.

43. Fray Gaspar DE CARVAJAL, Descubrimiento del río de las Amazonas, op. cit., p. 27.

44. Bernal díAz del CASTILlo, Historia verdadera de la conquista de la Nueva España, México, Pedro Robredo, 1939, p. 58.

45. William F. HANKS, «Language and discourse in colonial Yucatán», en Serge Grucinski y Nathan Wachtel (dirs.), Le Nouveau Monde. Mondes nouveaux. L'expérience américaine, Paris, Éditions de l'École des Hautes Études en Sciences Sociales, 1996, p. 257.

46. Vladimir JANKÉLÉVITCH, Le Je-ne-sais-quoi et le presque-rien. T. 2. La méconnaissance. Le malentendu, op. cit., p. 189.

47. Bartolomé DE LAS CASAS, Historia de las Indias, op. cit., p. 437 y 439.

48. Ibid., p. 434.

49. Icíar ALONSO ARAGUÁs, Intérpretes de indias: La mediación lingüística y cultural en los viajes de exploración y conquista: Antillas, Caribe y Golfo de México (1492-1540), Tesis doctoral, Universidad de Salamanca, 2005, p. 225.

50. Esta consideración de la crónica de Indias como servicio a la Corona aparece claramente expresada en el proemio de los Naufragios de Álvar Nuñez CÁBEZA DE VACA (Álvar Nuñez CÁBEZA DE VACA, Naufragios, op. cit., p. 63-65).

51. Stephen GREENBLATT, «Learning to curse. Aspects of linguistic colonialism in the sixteenth century», in Learning to curse. Essays in early modern culture [1990], New York, Routledge, 2007, p. 39.

52. Bartolomé DE LAS CASAS, Historia de las Indias, op. cit., p. 264.

53. John H. ЕLLIOT, El Viejo Mundo y el Nuevo. 1492-1650, op. cit., p. 40.

54. José DE ACOSTA, Historia natural y moral de las Indias, Madrid, Alonso Martín, 1608, p. 243.

55. Cristóbal colón, Diario de a bordo, op. cit., p. 122.

56. Ibid., p. 149.

57. Ibid., p. 169.

58. Ibid, p. 92.

59. José DE ACOSTA, De procuranda indorum salute, op. cit., p. 249.

60. Éric ROULET, L'évangélisation des Indiens du Mexique. Impact et réalité de la conquête spirituelle au $\mathrm{XVI}^{e}$ siècle, Rennes, Presses Universitaires de Rennes, 2008, p. 241.

61. Pablo Joseph DE ARRIAGA, Extirpación de la idolatría en el Perú, Lima, Librería San Martí, 1920, p. 67. 
62. William F. HANKS, «Language and discourse in colonial Yucatán» dans Serge Grucinski et Nathan Wachtel, Le Nouveau Monde. Mondes nouveaux. L'expérience américaine, Paris, Éditions de l'École des Hautes Études en Sciences Sociales, 1996, p. 259.

63. Franco LA CECLA, Le malentendu, Paris, Balland, 2002, p. 29.

64. Ibid., p. 14.

65. José DE ACOSTA, De procuranda indorum salute, op. cit., p. 255.

66. Diego dURÁN, Historia de las Indias de Nueva España e Islas de Tierra firme, México, Porrúa, 2005, Vol. I-II, p. 3.

67. Robert RICARD, La conquête spirituelle du Mexique. Essai sur l'apostolat et les méthodes missionnaires des Ordres Mendiants en Nouvelle Espagne de 1523-24 à 1572, Paris, Institut d'Ethnologie, 1933, p. 48.

68. Ibid, p. 75.

69. Serge GRUZINSKI, La colonisation de l'imaginaire. Sociétés indigènes et occidentalisation dans le Mexique espagnol (XVI ${ }^{e}-\mathrm{XVIII}{ }^{e}$ siècle), Paris, Gallimard, 1988, p. 241.

70. Emma MARTINELL GIFRE, La comunicación entre indios y españoles: palabras y gestos, op. cit., p. 105.

71. Robert RICARD, La conquête spirituelle du Mexique, op. cit., p. 50.

72. Carlos DISANDRo y Jorge STREET, La Compañía de Jesús contra la Iglesia y el Estado, La Plata, Ediciones Hostería volante, 1970, p. 72.

73. Bernardino DE SAHAGÚN, Historia general de las cosas de Nueva España, México, Imprenta del Ciudadano Alejandro Valdés, 1830, p. 321-322.

74. Franco LA CECLA, Le malentendu, op. cit., p. 89.

\section{RESÚMENES}

L'article analyse l'importance des malentendus linguistiques et culturels pendant la conquête et la colonisation de l'Amérique par les Espagnols. La diversité linguistique du Nouveau Monde fut un défi majeur pour le projet colonisateur, fondé sur le besoin de communiquer pour mieux donner des ordres à la population locale et imposer la culture de la métropole. La confiance en la capacité de comprendre et de se faire comprendre fut à l'origine de nombreux malentendus ethnocentriques, dans lesquels l'altérité indigène était systématiquement niée. Cependant, les malentendus furent aussi féconds, dans la mesure où ils contribuèrent à préserver les cultures autochtones de l'assimilation totale et à générer des phénomènes de syncrétisme, impliquant la négociation et l'échange.

This paper examines the importance of linguistic and cultural misunderstandings during the Spanish conquest and colonization of America. The linguistic diversity of the New World was a paramount challenge for the colonial project, based upon the need of communicating in order to give orders to the local population and to impose the culture of the Metropole. The belief in the capacity to understand and to be understood originated numerous ethnocentric misunderstandings, in which the indigenous otherness was systematically denied. However, misunderstandings were also productive, inasmuch as they contributed to preserve the autochthone cultures from total assimilation and to spin off syncretic phenomenon which implied negotiation and exchange. 
ÍNDICE

Mots-clés: malentendu, interculturalité, communication, traduction, relations entre Espagnols et Indigènes, conquête de l'Amérique

Keywords: misunderstanding, interculturality, communication, translation, relationship between Spaniards and Indians, conquest of America

\section{AUTOR}

MARCOS EYMAR

Université d'Orléans 